\title{
Monitoring Radioactivity in the Environment Under Routine and Emergency Conditions
}

\author{
De Cort Marc \\ European Commission, JRC, Institute for Transuranium Elements, Ispra \\ Italy
}

\section{Introduction}

The main purpose of environmental monitoring is to quantify the levels of radioactivity in the various compartments of the environment disregarding its origin: natural or anthropogenic, under routine or accidental conditions, in view of assessing the health effects on man and his environment. However, because of their historical background, which is connected to the development of nuclear industry, the monitoring programmes established in the European countries focus on artificial radioactivity.

Man-made radioactive matter can get into the biosphere by means of legally permitted discharges from nuclear installations or infrastructures where radioactive material is being used, e.g. hospitals and industry, or as the result of an accident. For each cause, specific sampling and monitoring programmes, as well as systems for internationally exchanging their results, have been implemented in the European Union and are still evolving.

Routine monitoring is done on a continuous basis throughout the country by sampling the main environmental compartments which lead to man; typically these are airborne particulates, surface water, drinking water and food (typically milk and the main constituents of the national diet). The aim of routine monitoring is then also to confirm that levels are within the maximum permitted levels for the whole population (Basic Safety Standards, (EC, 1996)) and to detect eventual trends in concentrations over time. A comprehensive overview of the sampling strategies and principal measurement methods in the countries of the EU will be given, as well as how this information is communicated to the general public.

In case of an accident, monitoring (i.e., sampling, measuring and reporting) is tailored to the nature of the radioactive matter released and to the way in which it is dispersed. In particular during the early phase of an accident with atmospheric release it is essential to be able to delineate the contamination as soon as possible to allow for immediate and appropriate countermeasures. Afterwards, once the radioactivity has deposited, it is important to have detailed information of the deposition pattern; a detailed deposition map at a fairly early stage will serve to steer medium and long term countermeasure strategies (e.g. agricultural, remediation). A summary of the most commonly used techniques, as well as a discussion of the various sampling network types (emergency preparedness, mobile) will be given.

The Chernobyl NPP accident on 26 April 1986 also triggered the European Commission to develop, together with the EU Member States, systems for the rapid exchange of information in case of a nuclear/radiological accident (European Community Urgent Radiological Information Exchange (ECURIE), European Radiological Data Exchange Platform (EURDEP)). Also these systems will be further described. 


\section{Types of monitoring networks}

Depending on the risk, networks have been developed for various purposes. In the first place there is the monitoring of radioactivity releases at nuclear installations, which aims at verifying the authorised discharges. In addition, in most European countries an environmental monitoring programme is operated for the main compartments of the biosphere, i.e., air, water, soil, foodstuffs. The purpose of such an environmental radioactivity monitoring programme is to verify compliance with the basic safety standards for the public.

However, this objective is influenced by the source of radioactivity as well as the environmental compartment(s) affected. Radioactive material mainly comes into the environment by means of discharges into the atmosphere and/or the water. These discharges can happen in a controlled or in an accidental way. Therefore a distinction should be made between routine and emergency situations. In general one can distinguish between the following types of monitoring networks:

- $\quad$ surveillance monitoring networks around nuclear installations to ensure that releases to the atmosphere and acquatic compartment remain below authorized limits, and to verify potential, chronic accumulation of radioactivity in the environment. Results obtained in this way may be used to estimate radiation exposure to critical groups (i.e., members of the public who have been identified as likely to receive the highest doses) (Hurst \& Thomas, 2004). In case of accidental release, these networks can also provide information about the off-site contamination close to the installation, usually by means of ambient dose rate or by air concentration measurements;

- national surveillance networks that generally cover the whole territory. These contribute to ensuring compliance with the basic safety standards for the population at large. These networks are operated on a national basis and cover the whole biosphere;

- $\quad$ emergency preparedness networks continuously check levels of mainly ambient dose equivalent rate and airborne radioactivity, in order to detect accidental releases and subsequently monitor the evolution of the radioactive plume. Depending on the country, the monitors belonging to these networks are positioned along national borders and/or distributed over the national territory;

- mobile equipment: depending on the size and the type of accident (release into the air and/or the aquatic phase, types of radionuclides dispersed etc.), additional mobile equipment (terrestrial or airborne) will be needed to obtain more detailed information for more highly contaminated areas.

Whereas the first two types of network mainly have been designed for routine conditions, the latter two types have been designed in view of accidents. Most of the information during the early (or release phase) of an accident will come from the emergency preparedness network and to a lesser extent from the national surveillance networks.

Ideally, an emergency monitoring strategy combines routine monitoring procedures with special requirements set by the emergency e.g. by combining measurement results from fixed monitoring stations (static network) with those from mobile or intervention teams.

During the aftermath of an accident, emergency monitoring is not only important for effective post accident management but also to reassure the general public. Therefore, during a nuclear emergency the measuring and laboratory activities, as well as the general preparedness to perform situation analysis, are enhanced and intensified and special measuring systems (in particular mobile monitoring equipment) are used when appropriate (Lahtinen, 2004). 


\section{Environmental sampling and measuring techniques}

\subsection{Exposure pathways}

Atmospheric discharges may result in exposure from four pathways, leading to doses to the population:

- external contamination;

- inhalation;

- ingestion;

- external radiation.

To estimate the consequences of the external contamination and inhalation pathways, monitoring by air sampling is performed. For the ingestion pathway this happens by of means of food sampling, e.g., milk, whereas external radiation is determined by direct measurements of external dose or by soil analysis.

Liquid discharges may irradiate man through three pathways:

- ingestion;

- external contamination;

- external radiation.

The monitoring of dose from ingestion in this case is usually carried out through sampling of fish and shellfish. The other two pathways are monitored by sampling of water, aquatic bio-indicators (e.g., seaweed, fish, molluscs) and sediments, and by direct measurements of doses from handling fishing gear or residing on beaches (Aarkrog, 1996).

Internal contamination, as a result of inhalation and/or ingestion, can also be measured directly by whole body counting equipment (see also section 4.4.3.1). In specific radiological situations, like in the case of contamination with pure alfa and beta emitting radioisotopes, monitoring of the internal contamination can be performed by analysis of the blood, urine and/or faeces.

\subsection{Air}

\subsubsection{Introduction}

The purpose of monitoring airborne radioactivity in the environment is to check domestic and foreign facilities. Depending on the meteorological conditions, airborne radioactive material can be rapidly transported over long distances in any direction. Man can become contaminated immediately through inhalation or external contamination, or indirectly by deposition and transfer of the radionuclides into the food chain. Therefore, monitoring the air is particularly important in order that contamination be detected as early as possible.

In general, one distinguishes two sampling and measuring techniques for air:

- particulates (alpha/beta or nuclide specific);

- gases (e.g., gaseous iodine, noble gases).

Airborne particulate radioactivity concentration is difficult to measure directly, since the artificial activity concentrations are typically lower than the natural radioactivity concentrations. Therefore accumulation methods are being used. The airborne dust is collected by drawing air through a filter material, which can be made of paper, glass fibre or polypropylene. The sampling devices may be located in diverse environments (in an open field or a courtyard, at ground level or on the roof of a building), which however complicates the intercomparability of measurements and their representativeness. Natural radionuclides include radon and its short-lived decay products (typically $1-20 \mathrm{~Bq} \cdot \mathrm{m}^{-3}$ in outdoor air), ${ }^{7 B e}$ and ${ }^{40} \mathrm{~K}$.

Depending on the response time of the measurement systems, one should make a distinction between on-line and off-line sampling/measuring devices. 


\subsubsection{On-line measurements}

Based on the nuclide category to be measured, generally two measuring methods are considered:

\section{Alpha/beta measurements:}

Large area proportional counter tubes are used to measure the accumulated activity. Fixed filter devices only permit sampling periods of maximum one week and require thus considerable operational service. Automated filter changing mechanisms allow automatic operation up to six months and are particularly used in automatic monitoring networks; their drawback, however, is that they require regular maintenance. It is common practice for monitors to have flow rates of up to $25 \mathrm{~m}^{3} \cdot \mathrm{h}^{-1}$, and detect artificial alpha and beta activity concentrations down to $0.1 \mathrm{~Bq} \cdot \mathrm{m}^{-3}$ in less than one hour in a natural background of several $\mathrm{Bq} \cdot \mathrm{m}^{-3}$. By increasing the filter speed (in case of a ribbon filter) or by increasing the frequency of the filter exchange, one is able to measure up to $106 \mathrm{~Bq} \cdot \mathrm{m}^{-3}$ (Frenzel, 1993).
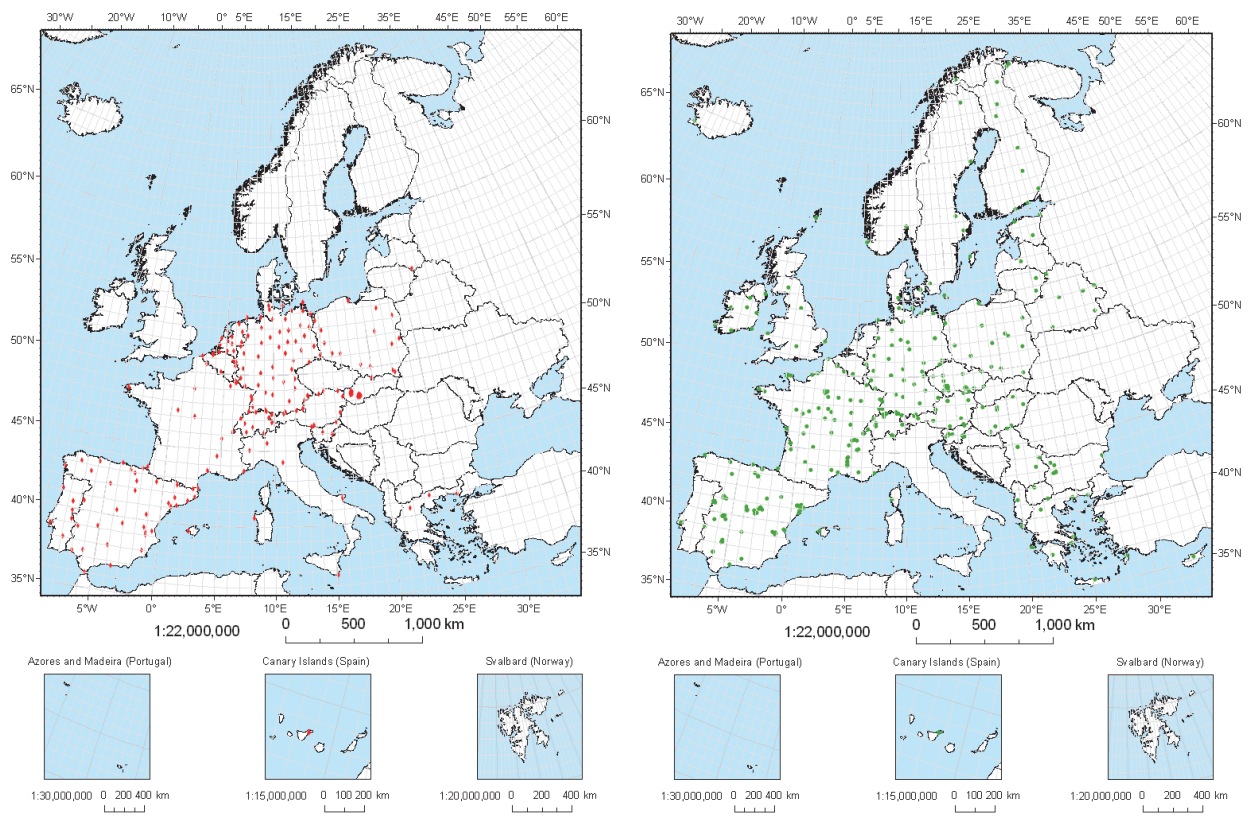

Fig. 1. On-line (left) and off-line (right) aerosol monitoring networks in a number of European countries (Bossew, P. et al, 2008)

Widely used measuring methods are:

- gross alpha: i.e., total alpha minus natural alpha radioactivity. The measurement is made by gas flow proportional counters, with or without anti-coincidence. Lower detection limits range between $1 \times 10^{-5}$ and $4 \times 10^{-2} \mathrm{~Bq} \cdot \mathrm{m}^{-3}$;

- gross beta: i.e., total beta radioactivity with correction for natural radioactivity (mostly influenced by radon daughters). The measuring instruments used are: Geiger-Müller, gas flow proportional counter with different active surfaces and plastic scintillators with ZnS coating for simultaneous coincidence of alpha contamination. Depending on the methods 
used, the lower detection limits range between $5 \times 10^{-5}$ and $1 \mathrm{~Bq} \cdot \mathrm{m}^{-3}$. Distinction between natural and artificial radioactivity can be done very effectively by simultaneous coincidence counting of alpha decay and by assuming that there is no contribution of artificial alpha emitters. In this way concentrations of artificial radioactivity down to $0.1 \mathrm{~Bq} \cdot \mathrm{m}^{-3}$ can be detected. One may also perform a second, delayed beta-counting after, e.g., $12 \mathrm{~h}$ (most short-lived daughters, except $212 \mathrm{Po}$, will then have decayed). This is a valid procedure for routine monitoring, but in emergency situations the alarm level will still be determined by the natural background (on the order of $10 \mathrm{~Bq} \mathrm{m-3)}$ (Janssens et al, 1991).

Nuclide specific (gamma) measurements:

The filter is measured by solid state detectors:

- semi-conductor detectors (lithium drifted (GeLi) or high purity (HPGe) germanium detector); Measuring systems in inaccessible locations, such as high mountains or remote islands, become independent from the liquid nitrogen by using electrically cooled Ge detectors;

- $\quad$ or scintillation counters (NaI).

Nowadays nuclide-specific identifications are increasingly performed by means of high purity Ge detectors. To ensure optimum early warning, these instruments are designed to allow simultaneous alpha-beta measurement and nuclide-specific measurement. In the automatic mode, modern instruments are capable of reaching low detection limits $\left(50 \mathrm{mBq} \cdot \mathrm{m}^{-3}\right.$ for ${ }^{60} \mathrm{Co}$ in $1 \mathrm{~h}$ ) and can analyse spectra for up to 100 different nuclides. Mostly ${ }^{137} \mathrm{Cs}$ and ${ }^{60} \mathrm{Co}$ and some natural nuclides such as ${ }^{7} \mathrm{Be}$ are measured.

\subsubsection{Off-line measurements}

Artificial airborne radioactivity in the range of $\mu \mathrm{Bq} \cdot \mathrm{m}^{-3}$ cannot be detected by automatic instruments in 'real-time', since the natural radioactivity level is too high. Most institutes perform correction from natural radioactivity by waiting 2 to 5 days before measuring the filter, to allow for short-lived radon/thoron daughters to decay.

Typically, high-volume air samplers (HVAS) with air flow rates ranging from 100 to $1,000 \mathrm{~m}^{3} \cdot \mathrm{h}^{-1}$ collect airborne particulates during one week. In case of an emergency, the sampling frequency can be increased to daily. By means of gamma spectroscopy detection levels of a few $\mu \mathrm{Bq} \cdot \mathrm{m}^{-3}$ or less can be obtained (e.g., ${ }^{137} \mathrm{Cs}$ concentrations on the order of $0.1 \mu \mathrm{Bq} \cdot \mathrm{m}^{-3}$ can be measured in a $3 \times 10^{5} \mathrm{~m}^{3}$ filter sample). Chemical treatment of certain filters afterwards allows the analysis of pure alpha or beta emitters (e.g., ${ }^{239} \mathrm{Pu}$ and ${ }^{90} \mathrm{Sr}$ ) (Frenzel, 1993).

\subsubsection{Measuring gaseous components}

Iodine is selectively accumulated in the thyroid gland and retains special attention because of its potential health hazard. Iodine in air can be bound to aerosols or can be gaseous, each requiring special measuring techniques. When bound to aerosols, iodine is measured with techniques as described previously.

Gaseous iodine is sampled by means of special filters (e.g., silver impregnated activated carbon). The active carbon adsorbs and thus accumulates the gaseous iodine. The drawback of these filters is that, depending on the airborne iodine concentration, they become saturated and have to be replaced. This method may also be used for collecting noble gases (e.g., ${ }^{85} \mathrm{Kr}$ ). The active carbon cartridge surrounds the detector or is located directly next to it. The specific peak of $364 \mathrm{keV}$ of ${ }^{131} \mathrm{I}$ is usually measured with scintillation (NaI) detectors. Although HPGe detectors are used for measuring the contribution of different iodine radioisotopes, nowadays 131I concentrations in the order of hundreds of $\mathrm{mBq} \cdot \mathrm{m}^{-3}$ can be measured in 1 hour. 


\subsection{Surface water}

Surface water includes river, lake or sea water. It is one of the environmental compartments to which radioactive effluents from nuclear installations can be directly discharged. Some of the sampling methods are automatic and continuous and are designed to detect contamination of water purification stations by radioactive effluents from industrial and research laboratories, hospitals having a nuclear medicine, etc... (e.g., the Telehydroray system installed on French rivers, and the Belgian automatic monitoring system on the river Meuse (Debauche, 2004). These automatic devices are designed to perform total gamma counting and to measure concentrations of ${ }^{131} \mathrm{I},{ }^{99} \mathrm{mTc}$ and ${ }^{137} \mathrm{Cs}$ with detection limits in the order of $1 \mathrm{~Bq} \cdot \mathrm{l}^{-1}$.

The time and frequency of sampling is very important for rivers with large differences in seasonal hydrological variations. In all cases, additional information on the river flow rate is very important. Radionuclides can be found in the water phase and associated with suspended particles, becoming eventually incorporated into sediments and living species. Natural radionuclides in surface water include ${ }^{3} \mathrm{H}\left(0.02-0.1 \mathrm{~Bq} \cdot \mathrm{l}^{-1}\right),{ }^{40} \mathrm{~K}\left(0.04-2 \mathrm{~Bq} \cdot \mathrm{l}^{-1}\right)$ radium, radon and their short-lived decay products $\left(<0.4-2 \mathrm{~Bq} \cdot \mathrm{l}^{-1}\right)$.

For routine conditions, river water samples can be taken continuously (or daily) and are then bulked into monthly or quarterly analysis. Alternatively spot samples are taken periodically and analysed individually.

Some laboratories (e.g., in France) filter their surface water prior to measurement. Measurement is then performed on the filtered water and the suspended material separately. More elaborate chemical separations are needed for ${ }^{90} \mathrm{Sr}$, whereas ${ }^{3} \mathrm{H}$, which is also produced by nuclear industry, is measured after multiple distillation or electrolytic enrichment of the sample. Usually, residual beta (total beta less ${ }^{40} \mathrm{~K}$ activity) contamination is reported (De Cort et al., 2009), although there is a clear tendency in many countries to perform nuclide-specific measurements.

With the exception of tritium in rivers with nuclear industry, usually the levels of radionuclide contamination in surface water are below the detection limit, due to the diluting factor. Hence countries nowadays make more use of biological indicators (aquatic moss, molluscs, vegetation) as these organisms have the capacity to concentrate specific chemical (stable and radioactive) elements. Fish is also frequently sampled, being a better activity integrator in the longer term (Sombré \& Lambotte, 2004).

\subsection{Soil/sediments/deposits}

Airborne particulates are removed from the atmosphere by gravitational settling and turbulent transfer to ground surfaces (dry deposition) or by incorporation in or scavenging by rain droplets (wet deposition). The latter is the predominant process in European countries, and monitoring networks do not generally measure the two components separately.

Depending on the circumstances and the objectives of the measurement, deposition can be sampled and measured in many different ways:

- for routine measurements, the radioactivity is mostly accumulated on artificial collection surfaces, with active surface areas ranging from 0.05 to $10 \mathrm{~m}^{2}$. The materials used for the collecting areas vary (stainless steel, plastic, polyester, PVC). In most cases these are designed for collecting precipitation. Some detectors distinguish between wet and dry deposition (they open and close appropriately in response to rainfall), but most sample total (wet + dry) deposition. The rainwater may be directly fed to a bottle or to an ion exchange column where the nuclides are fixed. Measuring the activity in the collected rainwater and the amount of rainfall allows calculating the average total 
deposition during the sampling period. Between the different European countries sampling periods range from daily, over weekly to monthly (De Cort et al., 2009);

- in case of emergency with large transboundary release to the atmosphere, vast areas can be contaminated. Once the radioactive material has deposited, it is important that, in order to determine appropriate countermeasures in the immediate post-accident management period and to reassure the public, rapid and reliable monitoring of contaminated areas is performed. Airborne gamma ray spectrometry is a fast and effective means to monitor large areas for deposited radioactivity. It is performed by solid-state detectors (usually by means of high volume scintillation detectors (NaI), high purity germanium detectors or a combination of both) mounted on an aeroplane or helicopter that flies at constant speed and low altitude (typically 50-100 m). Along the flight track, time-integrated gamma ray spectra (typically $1 \mathrm{~s}$ ) are recorded which, along with the information obtained from on-line GPS and radar-altimetry for automatic position and height correction, allow terrestrial radioactivity levels to be quantified and mapped. One of the main sources of uncertainty arises from the uncertainty in the activity depth distribution in the soil. Most commonly nowadays calibration is done by comparison with ground based spectrometry on representative radiation fields. Beyond its obvious benefits in case of a large nuclear accident, airborne gamma ray spectrometry is also applied for geological mapping for mineral exploration, soil mapping for agriculture, pollution studies and lost sources. (Dickson, 2004)

- core sampling is a conventional technique and together with high resolution spectrometry it can be highly accurate and sensitive. It is the only method for radioisotopes which do not emit gamma rays (eg. ${ }^{90} \mathrm{Sr}$ ). It serves as an indicator of long-term build-up of radioactivity in the environment and is therefore essential for studies of vertical profiling and measurements by alpha, beta or mass spectrometry. It has the drawback of being time-consuming. Migration in the soil depends on the chemical form of the radionuclide, the soil type, hydrology and agricultural practices. Most artificial radionuclides are found in the upper $30 \mathrm{~cm}$ soil layer. Because of the possibility of large micro-scale variations in deposition, it is important to take a sufficient amount of soil samples in order to obtain a reasonable estimate of the deposition of radioisotopes at a given site. Subsequently the samples are thoroughly mixed in order to obtain a representative aliquot which can then be further analysed and measured (Aarkrog, 1996);

- in-situ measurements, where a gamma spectrometer is placed at $1 \mathrm{~m}$ above the ground, properly shielded by lead to measure in solid angle and thus reducing ambient gamma radiation (Raes, 1989). In-situ gamma-spectrometry measurement of the mean surface radioactivity concentration for a large area $(\sim 1 \mathrm{ha})$ in a relatively short time (generally 1530 minutes for a deposition of $10 \mathrm{kBq} \mathrm{m}{ }^{-2}$ of ${ }^{137} \mathrm{Cs}$ ) (Dubois \& Bossew, 2003). The uncertainty of the measurement is influenced by local topographic variations (buildings, trees,...), by vegetation cover and by the vertical activity distribution of the radionuclide. Good results have been obtained by means of an advanced analysis of the measured gamma spectrum, referred to as 'Peak-to-valley' method (Gering et al., 1998; Tyler, 2004). In-situ measurements are also common practice in emergency preparedness networks where gamma dose-rate detectors (usually Geiger-Müller probes, proportional counters, ionisation chambers) monitor continuously the ambient gamma dose-rate.

- herbage is also a readily available indicator of deposition and of incorporation into green vegetables. Furthermore herbage forms part of the milk pathway to man (Hurst \& Thomas, 2004). 


\subsection{Food chain}

\subsubsection{Drinking water}

Radioactivity in drinking water is an important indicator of radionuclide transfer from the environment to man. The most important natural radionuclides in water for drinking consumption are ${ }^{3} \mathrm{H}\left(0.02-0.4 \mathrm{~Bq} \mathrm{l}^{-1}\right),{ }^{40} \mathrm{~K}$ (typically $0.2 \mathrm{~Bq}^{-1}$ but widely variable), radium, radon and their short-lived decay products $\left(0.4-4 \mathrm{~Bq}^{-1}\right)$.

The sampling of drinking water varies in the European countries, depending on the national water resources and distribution systems. Drinking water thus may be sampled from ground or surface water supplies, from water distribution networks, mineral waters and table water in bottles. After sampling, the water is mostly evaporated for direct measurement of the residue or is separated on ion-exchange columns. More elaborate chemical separations are needed for ${ }^{90} \mathrm{Sr}$, whereas ${ }^{3} \mathrm{H}$ is measured by liquid scintillation after purification of the water sample by multiple distillations (De Cort et al., 2009).

The European Commission has issued a directive on water quality, including radioactive aspects. In particular, a limit of $100 \mathrm{~Bq} \mathrm{l}^{-1}$ of tritium and a total indicative annual dose of 0.1 $\mathrm{mSv}$ (natural radioisotopes not included) from water intended for human consumption has been established (EC, 1998). Member States are adapting their national monitoring programme to meet this demand.

\subsubsection{Milk}

Milk constitutes a principal pathway for exposure to airborne effluents. In addition it is an important foodstuff because it is produced continuously in large quantities, and it is consumed as such or it forms the basis for other foodstuffs (e.g., dairy products). It is essential for children, and the most important fission products such as ${ }^{90} \mathrm{Sr},{ }^{131} \mathrm{I}$ and ${ }^{137 \mathrm{Cs}}$ are secreted in it.

At national level, milk samples are mostly taken at dairies that cover large geographical areas (in order to obtain representative samples), at farms (from raw milk) or at the super market (from bottled milk). To complete the national programme, supplementary milk samples are usually collected at single farms close to nuclear installations. Generally the samples are taken on a monthly basis, but sometimes only over the pasture season. Usually the milk samples are dried before gamma spectrometric analysis. Chemical separation is applied for the determination of ${ }^{90} \mathrm{Sr}$ activity and separation of the water phase with subsequent distillation for the separation of ${ }^{3} \mathrm{H}$.

In addition, the concentrations of the stable isotopes $\mathrm{Ca}$ and $\mathrm{K}$ are determined because of the similarity of their metabolic behaviour with $\mathrm{Sr}$ and $\mathrm{Cs}$, respectively. Typical values in milk are 1 - $2 \mathrm{~g} \mathrm{l}^{-1}$ for Ca and 1 - $3.5 \mathrm{~g} \mathrm{l}^{-1}$ for K (De Cort et al., 2009).

In case of an accidental atmospheric release, only a few days after deposition occurred, radionuclides already reach their maximum activity concentration in the milk (eg 2-4 days for ${ }^{131} \mathrm{I}, 4-6$ days for ${ }^{137} \mathrm{Cs}$ or ${ }^{90} \mathrm{Sr}$ ) (Mercer et al, 2002). Hence immediate monitoring is required. However, in the immediate aftermath of an accidental release, some information may be available on the source and scale of the release, but it is very unlikely that any measurement data on environmental materials will be available.

Predictive models, eventually in combination with data on activity deposited in soil, are essential at this point to provide an initial estimate of the dispersion of the activity released. Estimates of the evolution of activity concentrations in milk are required in the early stages following an accident. These are determined by the time of the year the deposition occurred (greater contamination of milk in summer and autumn when cattle are grazing in the pasture or delayed contamination can occur when contaminated fodder has been harvested). 
Within this time, an extended monitoring programme with intensified sampling of milk at affected dairies would have to be started, and subsequently samples sent to laboratories. Results for gamma ray emitting radionuclides (eg ${ }^{131} \mathrm{I}$ or ${ }^{137} \mathrm{Cs}$ ) would be available within 1 hour, whereas the determination of pure beta emitters (like ${ }^{90} \mathrm{Sr}$ ) would require several days. An efficient alternative has been developed by the Radiation Protection Division/Health Protection Agency, UK. It consists of a portable specialised NaI detector to measure individual milk samples at bulking depots located in the vicinity of the contaminated area. Information on the radionuclide composition would be required to ensure a proper calibration of the measuring equipment. A minimum detection limit of $100 \mathrm{~Bq}{ }^{-1}$ within 100 $\mathrm{s}$ of counting time is achievable (Mercer et al, 2002).

Information on the radionuclide composition of the deposited activity is a priority for a sampling and measurement programme. This enables the radionuclides of primary radiological interest to be identified and the analytical strategy to be determined. Gammaemitting radionuclides can be determined rapidly without destroying the sample. However, it is also important to determine the contributions from beta emitters like ${ }^{89} \mathrm{Sr}$ and ${ }^{90} \mathrm{Sr}$. (Mercer et al, 2002)

\subsubsection{Foodstuffs}

Foodstuffs are measured as separate ingredients (e.g., cereals, meat, fish, vegetables and fruit) or as whole meals (e.g., in canteens of factories or schools). The reason for measuring ingredients is to complete the monitoring programme for migration of radionuclides in the food chain or to check contamination of the public at large through ingestion, whereas sampling the whole meal gives a more direct estimate of the dose received by the population through ingestion. For general surveillance programmes the latter is more representative for the ingestion dose of the population, although ingredient monitoring is generally applied to obtain information on the propagation of radioisotopes in the food chain. Ingredients are measured particularly in case of emergencies to monitor the evolution of radioactive contamination of specific foodstuffs.

In some European countries (e.g., Denmark, United Kingdom and Finland), an important programme for monitoring fish has been established. This is needed to determine radionuclide transfer in the aquatic environment. Usually, fish types most commonly caught for human consumption are sampled. They are sorted by their origin, species and size (Saxen 1990).

Because of differences in the composition of national diets, there is a tendency in the EU to sample complete meals at schools or factory canteens in order to give a representative figure for contamination in a mixed diet (expressed in Bq. $\mathrm{d}^{-1}$ per person). Knowledge of the contamination of the different ingredients together with the composition of the national diet can also lead to a representative figure for the radioactivity level in a mixed diet.

The radioactivity levels legally permitted in foodstuff in the EU are laid down in the appropriate EC legislation (EC, 1989; EC, 2000a). Monitoring of foodstuff in the aftermath of a large scale nuclear accident will require major and specific efforts, depending on the type and scale of the atmospheric release. Crop monitoring programmes can be significantly rationalised by using results from airborne gamma spectrometry surveys of the contaminated area, combined with appropriate food chain models.

In the long term it is important that specific food types continue to be monitored, in particular foodstuffs coming from affected areas, even when radioactivity contamination levels in agricultural products have returned to normal. Typical examples are semi-natural foodstuffs that concentrate Cs, such as mushrooms, reindeer (through lichen), wild boar and carnivorous lake fish (EC, 2003). 


\subsection{Ambient dose equivalent}

External radiation is measured as an instantaneous gamma dose-rate or a gamma dose integrated over a certain time period. It is non-nuclide specific and provides information covering large areas. For emergency preparedness purposes it is of specific importance as it can provide 'real-time' information about the progression of the radioactive cloud. Therefore all European countries already have or are establishing automatic monitoring networks for ambient gamma dose rate. Table 1 illustrates how the mean distance between stations ranges from approximately $10 \mathrm{~km}$ to $150 \mathrm{~km}$ (values for Iceland and Russia excepted because of the non uniform spatial distribution of the stations considered in this study).

\begin{tabular}{|c|c|c|c|}
\hline Country & Area $\left(1000 \mathrm{~km}^{2}\right)$ & No. stations & Mean distance* $(\mathrm{km})$ \\
\hline Albania & 29 & 5 & 76 \\
\hline Austria & 84 & 346 & 16 \\
\hline Belarus & 208 & 22 & 97 \\
\hline Belgium & 31 & 192 & 13 \\
\hline Bulgaria & 111 & 26 & 65 \\
\hline Cyprus & 91 & 7 & 36 \\
\hline Czech Republic & 79 & 413 & 14 \\
\hline Denmark & 43 & 13 & 58 \\
\hline Estonia & 43 & 10 & 66 \\
\hline Finland & 305 & 263 & 34 \\
\hline France & 544 & 157 & 59 \\
\hline $\begin{array}{c}\text { Former Yugoslav Republic } \\
\text { of Macedonia (FYROM) }\end{array}$ & 26 & 1 & 160 \\
\hline Germany & 357 & 2067 & 13 \\
\hline Greece & 132 & 24 & 74 \\
\hline Hungary & 93 & 77 & 35 \\
\hline Iceland & 103 & 5 & 144 \\
\hline Ireland & 70 & 14 & 71 \\
\hline Italy & 301 & 57 & 73 \\
\hline Latvia & 65 & 17 & 62 \\
\hline Lithuania & 65 & 21 & 56 \\
\hline Luxembourg & 2.6 & 18 & 12 \\
\hline Malta & 316 & 1 & 18 \\
\hline Netherlands & 34 & 191 & 13 \\
\hline Norway & 324 & 28 & 108 \\
\hline Poland & 313 & 35 & 95 \\
\hline Portugal & 92 & 17 & 74 \\
\hline Serbia \& Montenegro & 103 & 5 & 143 \\
\hline Slovak Republic & 49 & 63 & 28 \\
\hline Slovenia & 20 & 42 & 22 \\
\hline Spain & 505 & 914 & 23 \\
\hline Sweden & 411 & 35 & 108 \\
\hline Switzerland & 41 & 116 & 19 \\
\hline United Kingdom & 244 & 93 & 51 \\
\hline
\end{tabular}

* The mean distance is obtained by the square root of the surface of the national territory divided by the amount of monitors.

Table. 1. Number of automatic gamma dose-rate monitoring stations per country (Bossew, P. et al, 2008) 


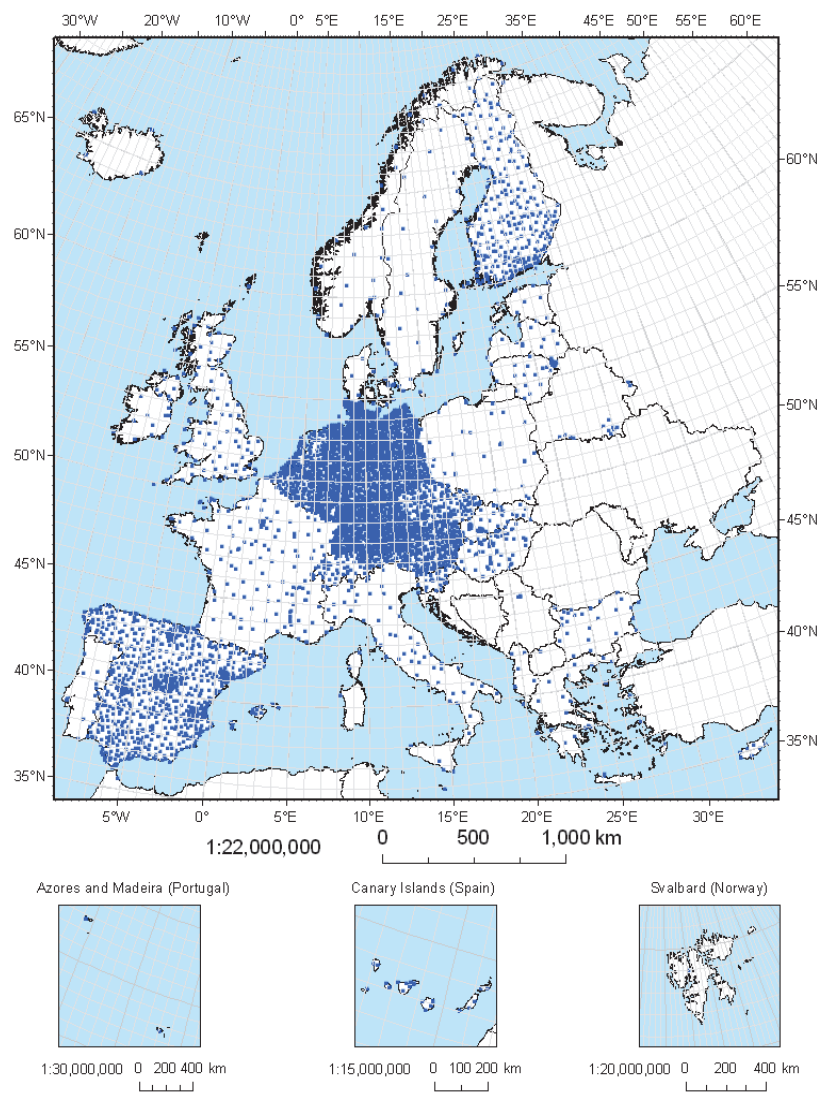

Fig. 2. Gamma dose rate monitoring networks in a number of European countries (Bossew, P. et al, 2008)

The detectors most frequently used are energy-compensated, gas-filled counter tubes, mostly Geiger-Müller (GM), ionization chambers and proportional counters. Occasionally scintillation detectors (NaI crystals) or even germanium spectrometers are used, in particular to determine the nuclide composition of the cloud by gamma spectroscopy. Some countries, e.g. Germany, are exploring to replace a part of their GM tubes by detectors that provide nuclide specific information of the ambient radiation, such as CdZnTe semiconductors that operate at room temperature.

In order to cover the measuring range from natural radiation up to high dose-rate levels encountered during accidental releases, two counters are usually built into a detector, one for low-range and one for high-range measurements. Modern detectors are equipped with local electronics for data transfer. They may also feature data storage and perform automatic background correction.

A drawback, however, is that local dose rate measurements are very sensitive, so that even minor variations of the natural radioactivity concentration can be detected (e.g., due to radon daughters during precipitation or a pressure drop - see Fig. 3.). 


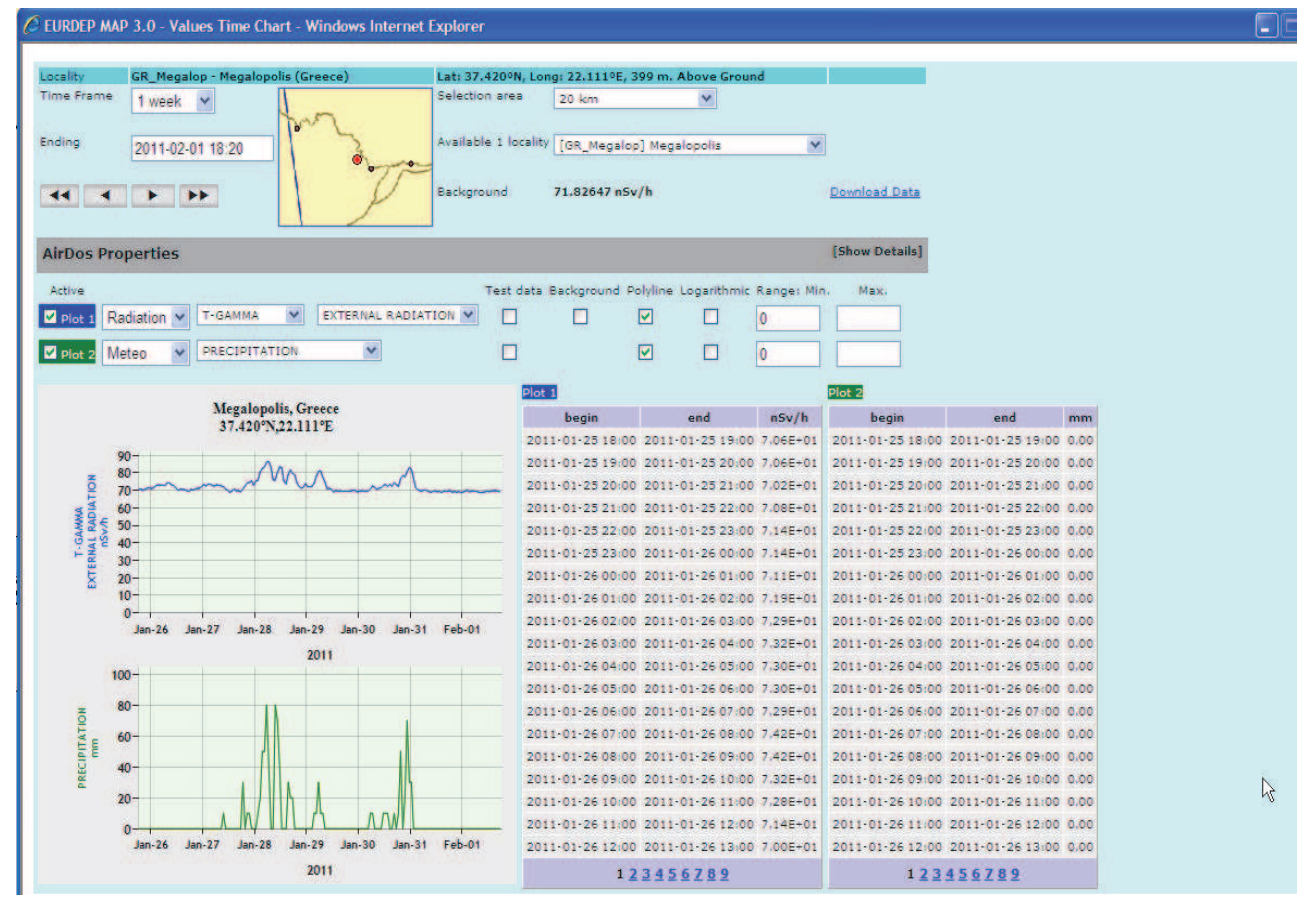

Fig. 3. Example of the effect of precipitation (lower left) on the ambient dose equivalent rate (middle left), due to radon daughter washout (http:/ / eurdep.jrc.ec.europa.eu)

Furthermore, time-integrated dosimeters (film badges and thermo-luminescent dosimeters (TLDs)) are used, mostly on the perimeter fence of nuclear installations in order to obtain a cumulative measurement of the direct gamma radiation of the plant. Results from film dosimeters have to be treated with care, especially for low doses. They may also be affected by temperature and humidity (Hurst \& Thomas, 2004).

\section{Monitoring networks}

\subsection{Legislative background - information exchange and access}

It is obvious that the use of radioactive and nuclear materials holds an increased risk for health. Therefore monitoring of environmental radioactivity is subject to strict legal obligations. This paragraph describes more into detail which legislation is in place and which measures have to be taken by the EU Member States.

It is normal practice to monitor not only exposure of critical groups but also to review exposure of the population at large. Within the European Community there is an obligation to do so both in terms of Article 35 of the Euratom Treaty and in terms of Article 13 and 14 of the Basic Safety Standards (EC, 1996).

Chapter III of the Euratom Treaty deals with Health and Safety aspects of the development and growth of nuclear industries and in particular with the establishment of uniform safety standards to protect the health of workers and of the general public. Article 35 deals with radioactivity levels in the air, water and soil. 
Consequently Member States have set up programmes to monitor radioactivity levels in the air, water and soil over their entire territory. The main responsibility for establishing an environmental monitoring programme lies with the Member States. Under Article 35 the Commission also has access right to the monitoring facilities in order to verify their operation and efficiency.

The authorities shall keep the Commission informed of radioactivity levels to which the population is exposed, by periodically communicating data obtained with the facilities referred to in Article 35. The data are transmitted to the Commission in accordance with Article 36 of the Euratom Treaty. The Commission adopted a Recommendation to Article 36 (2000/473/ Euratom) (EC, 2000b) which specifies in much more detail the sample type and corresponding nuclide measurements that should be reported on, as well as the sampling frequency and the way in which these data have to be submitted to the European Commission. The routine environmental monitoring data are transmitted by the European Union (EU) Member State authorities to the Radioactivity Environmental Monitoring (REM) data base. This database is the basis for preparing the annual reports describing the radioactivity levels in the EU. Both REM database and the annual reports can be consulted by the public (http://rem.jrc.ec.europa.eu).

The vastness of the radioactive contamination following the Chernobyl accident also emphasized the need for improved international collaboration on emergency response. Shortly after the accident a legal framework was realised by establishing common international procedures for notification, data and information exchange and mutual assistance (i.e., the Conventions on Early Notification and Early Assistance by the International Atomic Energy Agency, and Council Decision 87/600 of the European Commission); these procedures were subsequently adopted in the national legislation of the Member States. The official notification system of the EC is the ECURIE system, which is the technical implementation of Council Decision 87/600. An EU Member State that in case of a radiological or nuclear emergency decides to take countermeasures to protect its population against an increase of radioactivity must promptly notify the European Commission. Upon receipt and verification, the EC will immediately forward this information to all Member States, after which the latter are required to inform the EC at appropriate intervals about the measures they take and the radioactivity levels they have measured.

EURDEP is a system by which automatic monitoring results (currently mainly ambient dose equivalent rate, but also air concentration data) are exchanged, irrespective of an emergency situation or not. Countries using EURDEP are exempted of sending the same radioactivity measurement results by ECURIE.

Although it has been designed originally for Europe, there are concrete plans between the EC and IAEA to extend the system to a world-wide coverage. At this moment about 4400 detectors in 35 European countries exchange continuously gamma dose rate measurements. The information can also be accessed by the public (see http:/ / eurdep.jrc.ec.europa.eu)

\subsection{Routine monitoring}

The routine monitoring programme, which has been developed in parallel to nuclear industry, essentially aims at verifying:

- the discharge authorisation of nuclear installations;

- compliance with the dose limits or constraints laid down for protecting the population. 
Therefore one should distinguish between national monitoring programmes and surveillance of nuclear installations.

The national monitoring programme has been designed to verify compliance of the Basic Safety Standards. Hence the monitoring programme should aim at providing information on the overall dose received by the population at large. The monitoring network is therefore to be designed so that the results are representative on a national level. This means that sampling locations must be far enough from nuclear installations in order to avoid direct influence of discharges, that sampling must be made of all the compartments of the environment and that sampling intervals must be performed at time periods that allow verification of dose limits (EC, 1996).

In addition there are environmental monitoring programmes for nuclear facilities in operation. These depend on the type of discharges, whether into the atmosphere and/or to the water. Verification of releases from nuclear installations is best performed by installing equipment in the stack and in the liquid effluent discharge line of the plant. Monitoring stations installed in the immediate vicinity of the plant ensure independent but indirect verification by the authorities. A network located at short distance and in an appropriate number of wind directions and downstream of the discharge point in the river or sea, assures this. In addition, estimation of the actual doses received by the critical groups requires that local foodstuffs be sampled and analysed.

Usually, for routine conditions, radioactivity levels are below the detection levels so that there is a trend to make more use of bio-indicators such as lichen, aquatic mosses and algae to trace accumulated radioactivity (EC, 2000b).

\subsection{Emergency preparedness monitoring}

\subsubsection{The need for emergency preparedness monitoring}

Any notification message about an emergency at a nuclear facility, warning that a significant amount of radioactivity has been released or is likely to be released, should come from the plant operator. This information will then be further disseminated through the proper communication channels on regional, national and international level (De Cort et al, 2007). Nevertheless many countries have set up mechanisms for early warning based on nationwide gamma dose-rate monitoring networks. This would allow the emergency situation to be identified independently and irrespective of whether the release was of domestic or foreign origin.

For this purpose it is necessary to be able to identify the source and to circumscribe the extent of the radioactive cloud with reasonable accuracy. Identification and circumscription are possible only if the density of the network is sufficiently high and if data from neighbouring countries can be relied upon in case of a transboundary movement.

\subsubsection{Network design criteria}

The basic requirement of an emergency preparedness network is its 'early-warning' capability, by which is meant that it must be able to detect a cloud resulting from an accidental release. Next it must be able to delineate the extent of the cloud and to track its progression over a territory.

Although they are mainly designed for the early detection of accidental releases, gamma dose-rate monitoring networks have limited value for circumscribing and monitoring the evolution of such clouds because they cannot readily discriminate between airborne and deposited radioactivity. Continuous aerosol monitoring devices are therefore preferred, 
but they have the drawback of having higher maintenance costs. Also out of financial budgetary reasons, a limited amount of gamma spectrometers is usually incorporated in an on-line network to give qualitative information about the composition of the cloud. After the passage of the cloud, the latter in combination with the gamma dose-rate readings, allow for the assessment of the amount of radioactivity deposited to the ground.

Gamma detectors, in view of their relatively low installation and maintenance cost and wider range of sensitivities, best serve the alarm function of the national monitoring networks. Geiger-Müller detectors, proportional counters, ionisation chambers or scintillation crystals may equally be preferred. The existence of so many systems has the drawback of differences in energy response. For the mere alarm function an accurate calibration (and knowledge of the nuclide composition of the cloud) is not a priority, but when absent, it may create problems when data from different networks are brought together.

Irrespective of the topology of the network, the representativeness of the gamma dose-rate measurements depends on many factors, such as the presence of trees (which enhance dry deposition), the presence of surfaces that promote surface runoff of radioactive material reavenged by precipitation (e.g., paved surfaces, roofs), attenuating obstructions (e.g., vicinity of buildings, walls), the surface roughness and the detector position above ground (e.g., terrain or roof). Differences of more than one order of magnitude may occur between different sites which have been contaminated under the same conditions. As is shown in (Sohier, 2002), these differences can be characterised by environmental parameters, on which basis the measured data can be interpreted correctly. In addition this parameterisation could be used to improve harmonisation between different national networks.

When a network is being designed, a number of general factors should be taken into account:

\subsubsection{Natural background subtraction}

Gamma detectors are also very sensitive to variations in background count rates. Apart from regional variations for which corrections can be made, there are also slow and fast temporal variations due to the dependence of radon daughter concentrations in air and soil on meteorological parameters (e.g., an enhanced soil exhalation in case of a pressure front passing by or a cyclonic pressure drop, or washout of atmospheric aerosols in case of rain). Automatic data processing for pattern recognition of such phenomena or correlation is difficult and in general one relies on the judgement of the operator in the central station for data collection.

Nevertheless alarm levels can be set at dose rates on the order of $100 \mathrm{nSv} \mathrm{h}^{-1}$ above background, which is certainly low enough.

Continuous aerosol monitors are preferable because they are not affected by ground deposition. However they consist of moving and consumable parts, so maintenance costs are higher. Continuous beta monitoring can be performed, e.g., by putting a beta detector in front of a slowly rotating paper ribbon. As already mentioned in section 3.2.2, there is the additional complication of having to subtract counts from radon daughters.

A distinction between natural and artificial radioactivity can also be achieved by gamma ray spectroscopy. Knowledge of the radionuclide composition of the release is of interest for predicting further transport and deposition of the cloud and for assessing population doses. The composition is not likely to vary quickly in the course of time, so it is sufficient to 
perform such measurements only in a few stations. Detection levels achieved by sampling on step-feed filters and on-line counting with a germanium detector are on the order of 0.05 $\mathrm{Bq} \mathrm{m}^{-3}$ (typically 2 hours measuring time).

\subsubsection{Sampling/counting time}

For continuous monitoring systems sampling and counting times are identical. In view of the alarm function of such systems one might be tempted to reduce the sampling/counting time at the expense of statistical error which in turn would demand an increase in alarm levels. This is particularly true for continuous beta detectors. In the case of gamma detectors it is to a large extent possible to choose a more sensitive instrument.

Counting times should nevertheless be sufficiently short so that the network yields information on the speed, direction and longitudinal elongation of the cloud. On the other hand, counting times too short may cause the central processing unit to be overloaded with redundant data, i.e., the 'pace' of the network (average distance between the stations divided by the sampling time) should be comparable to the wind velocity.

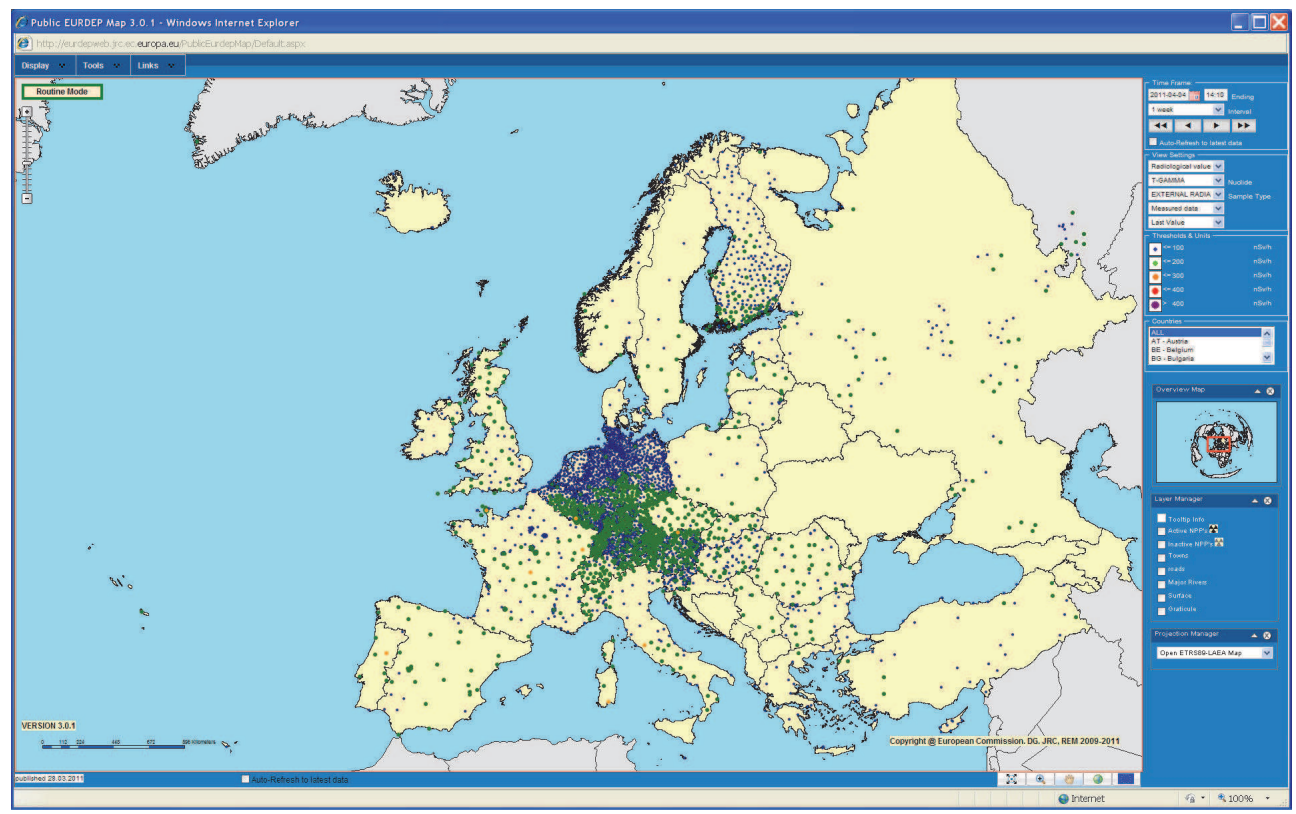

Fig. 4. Location of automatic gamma dose-rate monitoring stations that contribute to the EURDEP system (situation of April 2011), showing the topographic diversity of the national emergency preparedness networks.

\subsubsection{Spatial homogeneity}

The detection capacity of a network also depends on its spatial homogeneity. An elegant analysis of the impact of homogeneous coverage of the territory and of the limited extent of the network (countries' dimensions) can be made in terms of the 'factual' dimension of both 
the network and the cloud. Such an analysis demonstrates the need for integrating networks on the largest possible scale and for comparable network densities (Raes et al., 1991; Sohier, 2002). Figure 4 which shows the automatic monitoring stations for gamma dose-rate that contribute to the EURDEP system, demonstrates the lack of spatial homogeneity between the national emergency preparedness networks.

\subsection{Monitoring after an accident}

\subsubsection{General considerations}

Even though a thorough analysis of continuous monitoring data may improve the accuracy of predicting further transport and dispersion of the cloud, which may prove critical for timely assessing its possible impact and for preparing adequate countermeasures, additional means are necessary in case of a real accident.

Early decisions such as exhorting the population to seek shelter could be based directly on reading of gamma detectors or aerosol monitors. Evacuation or the distribution of iodine tablets on the other hand might be considered either as a precautionary measure when a major release is expected or otherwise after the plume has passed, but only after the current radiological situation has been assessed. Static networks are inappropriate for this purpose because exposure pathways depend to a large extent on ground deposition. In the absence of rain and in case of a well-circumscribed cloud, calculated values for ground deposition may be available. However the Chernobyl accident has taught us that in case of rainfall one must cope with a patchy deposition pattern, which can be assessed only by portable and preferably mobile equipment.

\subsubsection{Monitoring strategies}

In case of a possible accidental release of radioactivity, the monitoring programme aims at answering the following questions:

- has an abnormal release occurred;

- $\quad$ is there an action to be taken;

- which remedial measures should be implemented.

As for operational monitoring the design of the programme depends on the nature of the environment which has received the contamination. It is, however, important in any emergency that the results are obtained relatively quickly, which means that rapid methods should be used for making measurements. This usually means a lower sensitivity and thus a greater risk of errors. On the other hand if the contamination is substantial, fast measurements are possible without losing much in sensitivity. Last but not least, at all times one should be aware that equipment can become contaminated, leading to incorrect measurements.

\subsubsection{Mobile equipment}

\subsubsection{Terrestrial equipment}

Vans have been fitted with all equipment needed for in-situ measurement of dose rates, and for collecting air samples with aerosol filters and charcoal cartridges, and possibly for soil and biological samples, and for their immediate counting and spectrometric analysis. The fitting of such vans, their maintenance, the provision and permanent training of personnel involves considerable costs. It is a matter of choice whether resources are allocated to the extension of static networks or to mobile equipment. 
The mobile equipment should also have adequate means of communication and data transmission with the co-ordination centres (GPS navigational instruments and radar altimeter).

The need for environmental radioactivity measurements in case of an accident is not limited to rapid and detailed assessments prior to the implementation of countermeasures. Also in case of a remote accident involving a moderate release, it will be necessary to perform a large number of measurements in different media in order to perform an accurate a posteriori assessment of its radiological impact. Such an assessment fulfils the need for adequately informing the public and may also serve scientific investigations.

These kinds of measurements may be pursued over longer periods of time. The assessment of the impact of short-lived nuclides such as iodine and ruthenium isotopes will be possible only if measurements are performed within a few weeks after the accident.

The direct monitoring of internal contamination of people is usually done by means of whole body counters (WBC). The monitoring infrastructure is usually of a stationary type and installed at nuclear power plants, fuel cycle plants, research centres, hospitals with nuclear medicine, etc... However certain countries, such as France, also dispose of mobile equipment, usually in the form of intervention trailers, for monitoring contaminated persons. This equipment consists of vehicles equipped with 'partially body counters' (e.g., thyroid, thorax) and some even with WBC capacity (including appropriate shielding to reduce the background radiation). Detection limits (e.g. $500 \mathrm{~Bq}{ }^{137} \mathrm{Cs}$ for 10 minutes and 100 $\mathrm{Bq}$ for 30 minutes counting time) are higher than those for fixed installations; however they allow inspectors to sort people according to their internal contamination. In order to make full use of these resources in case of emergency, the main problem is to have available enough personnel sufficiently trained to guarantee that this infrastructure is full used (Fiedler \& Voigt, n.d.).

\subsubsection{Airborne equipment}

During the release phase, given the limitations of ground-based monitoring equipment for three-dimensional circumscription of the cloud, aircraft may prove very useful to carry out an aerial mapping at higher altitudes, in particular above the mixing boundary layer (e.g., $1500 \mathrm{~m}$ ). As soon as the release has ceased, airborne gamma ray spectrometry allows for rapid monitoring of vast areas contaminated by radioactivity. The technique has been described in section 3.4. Since the Chernobyl nuclear power plant accident, many European countries have become capable of deploying measurement teams within hours of an accident being notified, in order to measure levels and pattern of deposited radioactive material. In view of combining national efforts in case of a large scale nuclear accident, European teams have been collaborating and exercising on various occasions over the past years. This capacity to act jointly and produce, in real-time, a composite map of an area in Southern Scotland has been demonstrated in the ECCOMAGS project (Sanderson et al, 2004).

\section{Discussion and conclusions}

Competent Authorities of the European Union Member States have to ensure that the exposure of their population is compliant with the Basic Safety Standards (EC, 1996). To reach this objective European countries have set up environmental monitoring programmes which provide continuously the basic information, i.e., the radioactivity levels in the various compartments of their environment. Subsequently the doses received by the population can be assessed by means of radioecological models. The latter thus play an important role in 
designing sound environmental monitoring programmes, including the definition of potentially important pathways and critical groups by determining the most representative sample types and sample locations (Vandecasteele, 2004). Also in the case of radiological or nuclear emergency, and based on the available monitoring and modelling information, Member States are required to submit emergency procedures and practices in accordance with the Basic Safety Standards. At this moment, the latter is being revised to allow for the new ICRP Recommendations (Publication 103) as well as to consolidate all EU radiation protection legislation in a single BSS Directive (Janssens, 2009).

Since the Chernobyl nuclear power plant accident, European countries continue to enhance their capacity and infrastructure to monitor radioactivity in their environment. They also continue to improve their capacity to transfer and handle the monitoring data in real time, combining them with radioecological models and/or decision support systems, in order to convert them into information based on which decisions may be made.

In case of an emergency with radioactive release to the atmosphere, during the release phase most of the information about the environmental contamination will come from the 'static networks', i.e., the emergency preparedness network and the routine monitoring networks, as these operate permanently. Such monitoring data, together with information about the release and appropriate models to forecast the atmospheric dispersion of the cloud, will be used by the authorities to decide on early countermeasures. However, atmospheric dispersion models can give rise to uncertainties in model results, which may lead to different approaches for early countermeasures on the national level. In order to harmonise the information coming from various countries and to work out a reconciled and comprehensive European long range atmospheric dispersion ensemble forecast, the ENSEMBLE system has been developed (http://ensemble.jrc.ec.europa.eu) by the European Commission Joint Research Centre. (Galmarini et al, 2008).

Once the release has stopped and the radioactive material is deposited, it is important to know, as soon as possible, the detailed deposition pattern of the affected areas. Airborne and in-situ gamma spectrometry is currently considered the most efficient way to do this. Combining such results with appropriate food chain models can significantly rationalise milk and crop monitoring programmes.

The vastness of the radioactive contamination following the Chernobyl accident also emphasized the need for improved international collaboration on emergency response. Shortly after the accident both the EC and the IAEA realised a legal framework for notification, data and information exchange and mutual assistance. This need to exchange monitoring data on international level raised questions regarding the representativeness of measurements coming from the various national monitoring networks. The current national monitoring networks are mainly based on historical, political and budgetary constraints. It is most unlikely that these will be converted into a unified operational European monitoring network. Hence the only practical and sustainable approach for the future is to harmonise to the maximum extent possible the data and information produced by these networks as far as they are to be exchanged on an international level. This means that we have to understand fully how monitoring is performed in the various European states. International intercomparison exercises only provide a part of the answer, as they mainly focus on the measurement aspect of monitoring, and usually do not address issues such as sampling and reporting techniques, including representativeness. Notwithstanding this, it is worthwhile to mention that a number of initiatives have already been taken to address this problem, in particular for measurements which are usually performed during the release phase or the 
early post-release phase (i.e., the environmental parameterisation of gamma dose-rate detectors and the European collaboration of airborne gamma-ray spectrometry teams).

\section{References}

Aarkrog, A. (1996). Sampling and monitoring techniques, In: IBC $2^{\text {nd }}$ residential training course on environmental radiation protection, 1996

Bossew, P.; De Cort, M.; Dubois, G; Stöhlker, U.; Tollefsen, T. \& Wätjen, U. (2008). AIRDOS Evaluation of existing standards of measurement of ambient dose rate; and of sampling, sample preparation and measurement for estimating radioactivity levels in air. Final Report, project AA N TREN/NUCL/S12.378241, JRC ref. N 218942004-04 A1CO ISP BE.

Debauche, A. (2004). Continuous radioactivity monitoring systems. From the pre-history of radioprotection to the future of radioecology, Journal of Environmental Radioactivity, Vol. 72, pp. 103-108

De Cort, M.; de Vries, G. \& Galmarini, S. (2007). International data and information exchange systems in Europe in case of radiological and nuclear emergencies, International Journal of Emergency Management, Vol. 4, No. 3, pp. 442-454

De Cort, M., Tollefsen, T., Marsano, A. and Gitzinger, C. (Eds.). (2009). Environmental Radioactivity in the European Community 2004-2006, EUR 23950 EN, Office for Official Publication of the European Communities, ISBN 978-92-12984-1, Luxembourg

Dickson, B. L. (2004) Recent advances in aerial gamma-ray surveying, Journal of Environmental Radioactivity, Vol. 76, No. 1-2, pp. 225-236

Dubois, G. \& Bossew, P. (2003). Spatial analysis of ${ }^{137 C s}$ in the environment: an overview on the current experience in Mapping radioactivity in the environment: Spatial Interpolation Comparison 1997, G. Dubois, J. Malczewski and M. De Cort (Eds.), EUR 20667 EN, Office for Official Publication of the European Communities, Luxembourg, pp. 21-36

EC (1989). Council Regulation of (Euratom) No. 2218/89 amending regulation (Euratom) No. 3954/87 laying down the maximum permitted levels of radioactive contamination of foodstuffs and feeding stuffs following a nuclear accident or any other case of radiological emergency, In: Official Journal of the European Communities L211 of 27 July 1989

EC (1996). Council Directive (96/29/euratom) of 13 May 1996 laying down basic safety standards for the health protection of the general public and workers against the dangers of ionizing radiation, In: Official Journal of the European Communities L159 of 29/06/96

EC (1998). Council Directive 98/83/EC on the quality of water intended for human consumption, In: Official Journal of the European Communities L330 of 05/12/1998

EC (2000a). Commission Regulation 616/2000 of 20 March 2000 amending Regulation (EEC) $737 / 90$ on the condition governing imports of agricultural products originating in third countries following the accident at the Chernobyl nuclear power station In: Official Journal of the European Communities L75 of 24/03/2000

EC (2000b). Commission Recommendation (2000/473/Euratom) of 8 June 2000 on the application of Article 36 of the Euratom Treaty concerning the monitoring of the level of radioactivity in the environment for the purpose of assessing the exposure 
of the population as a whole, In: Official Journal of the European Communities L191 of $27 / 07 / 2000$

EC 2003). Commission Regulation 2003/120/EC on the protection and information of the public with regard to exposure resulting from the continued radioactive caesium contamination of certain wild food products a consequence of the accident of Chernobyl nuclear power station, In: Official Journal of the European Communities L-47/54 of 21/02/2003

Fiedler, I. \& Voigt, G. (Eds.), (n.d.). Review of infrastructures and preparedness systems in France, Germany and United Kingdom for potential releases of radioactivity into the environment, deliverable 1 of the EC project SAGE, In: http://www.ecsage.net/D04_01.pdf, 30 April 2011, Available from http:/ /www.ec-sage.net/

Frenzel, E. (1993). Environmental Monitoring: State of the Measuring Technique and Outlook, Radioprotection, pp. 255 - 261, February 1993

Galmarini, S.; Bianconi R.; de Vries G. \& Bellasio R. (2008). Real-time moniotring data for real-time multi-model validation: coupling ENSEMBLE and EURDEP, Journal of Environmental Radioactivity, Vol. 99, pp. 1233-1241

Gering, F.; Hillmann, U.; Jacob, P. \& Fehrenbacher, G. (1998). In situ gamma-spectrometry several years after deposition of radiocaesium: II. Peak-to-valley method, Radiation Environ Biophys, Vol. 37, pp. 283-291

Hurst, M.J. \& Thomas, D.W. (2004). Report on radioactivity discharges and environmental monitoring the nuclear power stations during 1990, HS/NSOB/HP-R/003/91, Nuclear Electric, October 1991

Janssens, A. (2009). Progress with the revision of the EURATOM Basic Safety Standards and consolidation with other Community legislation, Annalen van de Belgische Vereniging voor Stralingsbescherming. Vol. 34, No. 3, pp. 173-187, ISSN 02505010

Lahtinen, J. (2004). Radiation monitoring strategy: factors to be considered, Radiation Protection Dosimetry (2004), Vol. 109, No. 1-2, pp. 79-82

Mercer, J. A.; Nisbet, A. F. \& Wilkins, B. T. (2002). Management options for food production systems affected by a nuclear accident. Task 4: Emergency Monitoring and Processing of Milk, NRPB-W15 (June 2002)

Raes, F. (1989). Monitoring of Environmental Radioactivity in the European Community: inventory of Methods and Development of Data Quality Objectives, EUR 12801, Office for Official Publication of the European Communities, Luxembourg, 1989

Raes, F.; Graziani, G. \& Girardi, F. (1991). A simple and fractal analysis of the European online network for airborne radioactivity monitoring, Environmental Monitoring and Assessment, Vol. 18, pp. 221-234

Sanderson, D.C.W.; Cresswell, A.J.; Scott, E.M. \& Lang, J.J. (2004). Demonstrating the European capability for airborne gamma spectrometry: Results from the ECCOMAGS exercise. Radiation Protection Dosimetry, Vol. 109, No. 1-2, pp. 119-125, ISSN 0144-8420

Saxen, R. (1990). Radioactivity of surface water and freshwater fish in Finland in 1987, STUK-A77, May 1990

Sohier A. (ed.) (2002). A European manual for 'Off-site Emergency Planning and Response to Nuclear Accidents', SCK-CEN report R-3594, December 2002, p.341 
Sombré, L. \& Lambotte, J. M. (2004). Overview of the Belgian programme for the surveillance of the territory and the implications of the international recommendations or directives on the monitoring programme, Journal of Environmental Radioactivity. Vol. 72, pp. 75-87

Tyler, A. N. (2004). High accuracy in situ radiometric mapping, Journal of Environmental Radioactivity, Vol. 72, No. 1-2, pp. 195 - 202

Vandecasteele, C. M. (2004). Environmental monitoring and radioecology: a necessary strategy, Journal of Environmental Radioactivity, Vol. 72, No. 1-2, pp. 17 - 23 


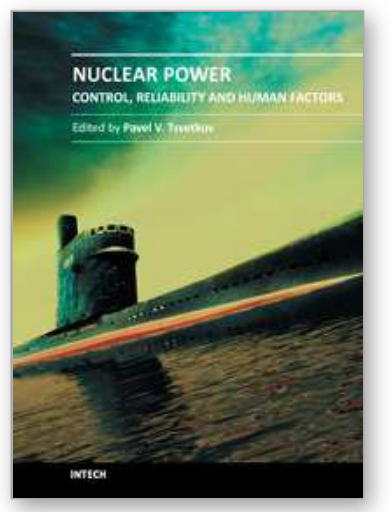

\author{
Nuclear Power - Control, Reliability and Human Factors \\ Edited by Dr. Pavel Tsvetkov
}

ISBN 978-953-307-599-0

Hard cover, 428 pages

Publisher InTech

Published online 26, September, 2011

Published in print edition September, 2011

Advances in reactor designs, materials and human-machine interfaces guarantee safety and reliability of emerging reactor technologies, eliminating possibilities for high-consequence human errors as those which have occurred in the past. New instrumentation and control technologies based in digital systems, novel sensors and measurement approaches facilitate safety, reliability and economic competitiveness of nuclear power options. Autonomous operation scenarios are becoming increasingly popular to consider for small modular systems. This book belongs to a series of books on nuclear power published by InTech. It consists of four major sections and contains twenty-one chapters on topics from key subject areas pertinent to instrumentation and control, operation reliability, system aging and human-machine interfaces. The book targets a broad potential readership group - students, researchers and specialists in the field - who are interested in learning about nuclear power.

\title{
How to reference
}

In order to correctly reference this scholarly work, feel free to copy and paste the following:

De Cort Marc (2011). Monitoring Radioactivity in the Environment Under Routine and Emergency Conditions, Nuclear Power - Control, Reliability and Human Factors, Dr. Pavel Tsvetkov (Ed.), ISBN: 978-953-307-599-0, InTech, Available from: http://www.intechopen.com/books/nuclear-power-control-reliability-and-humanfactors/monitoring-radioactivity-in-the-environment-under-routine-and-emergency-conditions

\section{INTECH}

open science | open minds

\section{InTech Europe}

University Campus STeP Ri

Slavka Krautzeka 83/A

51000 Rijeka, Croatia

Phone: +385 (51) 770447

Fax: +385 (51) 686166

www.intechopen.com

\section{InTech China}

Unit 405, Office Block, Hotel Equatorial Shanghai

No.65, Yan An Road (West), Shanghai, 200040, China

中国上海市延安西路65号上海国际贵都大饭店办公楼 405 单元

Phone: +86-21-62489820

Fax: $+86-21-62489821$ 
(C) 2011 The Author(s). Licensee IntechOpen. This chapter is distributed under the terms of the Creative Commons Attribution-NonCommercialShareAlike-3.0 License, which permits use, distribution and reproduction for non-commercial purposes, provided the original is properly cited and derivative works building on this content are distributed under the same license. 